\title{
Las sombras del mañana. La dimensión subjetiva de la política.
}

\section{NORBERT LECHNER}

Editorial LOM, Santiago de Chile 2002, 132 páginas.

En cierta medida, este último libro que alcanzó a publicar Norbert Lechner antes de su fallecimiento, es un resumen de su mirada respecto a los desafíos que la democracia latinoamericana enfrenta desde el período de transición en adelante. La obra mantiene la perspectiva singular del autor, en cuanto recupera elementos de la teoría europea y los adapta a la realidad latinoamericana. De hecho, el análisis de Lechner sobre la creciente autonomización de los sistemas funcionales y los efectos que esto tiene sobre la subjetividad, es un razonamiento heredero de la ya clásica disputa entre Habermas y Luhmann. Sin embargo, en este libro no sólo es recuperada esta disputa sino que a su vez es actualizada: los procesos de modernización erosionan los mapas cognitivos de la sociedad y, por lo tanto, la pregunta por el sentido individual y colectivo de la vida se vuelve apremiante. Por ello que la política se vea particularmente desafiada en el día de hoy. Ella intenta definir un horizonte colectivo de la acción en una época donde prima una imagen naturalizada de lo social, vale decir, donde decae el poder de la autodeterminación colectiva y aumenta la lógica de la autorregulación funcional de la sociedad.

Frente a este nuevo escenario, la pregunta de Lechner es la siguiente: ¿puede la política hacer algo más que velar por el buen funcionamiento de los sistemas? A juicio del autor, esto sólo se puede lograr en la medida que la política recupera la dimensión subjetiva de lo social. Más allá de los datos objetivos de la realidad (crecimiento económico, nivel de pobreza, etc.) hay una visión desde las personas sobre la existencia (miedos, sensaciones, etc.). La subjetividad indica cuáles son las expectativas de la ciudadanía acerca de lo que puede y debe producir el orden democrático. Quizás sean los políticos neo-populistas quienes más se han dado cuento de esto. Ellos establecen un vínculo mediático con las personas, en tanto reconocen y reivindican sus inseguridades y rabias, pero no proponen soluciones que pasen por una genuina deliberación colectiva. Tal como señala el autor: "el auge de la televisión y de la industria cultural tiende a transformar lo público' en 'los públicos'. Ahora hay múltiples públicos, segmentados según gustos, que tienen dificultades de encontrar un espacio común. Pero jes posible construir ciudadanía sin un espacio en común?" (pagina 33). 
Esta pregunta lleva a que el autor se cuestione en el último capítulo del libro si acaso es posible (re)construir un nosotros. Se trata de un proceso particularmente difícil en el día de hoy, ya que hay dos tendencias que atentan en su contra. Por una parte, la creciente especialización funcional hace que la imagen de la sociedad se defina a partir de la interacción entre una serie de sistemas y no tanto por las convivencias personales. Esto implica que el reflejo de lo que es la sociedad se vuelve abstracto, al punto tal que el habla de los ciudadanos hace constante referencia a 'el sistema'. Por otra parte, las transformaciones del último tiempo potencian la libertad negativa por sobre la libertad positiva. En la medida que las personas asumen el principio de la individualización (construcción biográfica de forma autónoma y reflexiva), la sociedad pasa a ser vista más como un estorbo que como un apoyo. Se deslegitima así lo colectivo y lo público, en tanto se supone que bastan las fuerzas individuales para conseguir el desarrollo.

En consecuencia, la pregunta de Lechner respecto a cómo (re)construir un nosotros equivale a saber cómo enfrentar la tendencia tanto de la autonomización sistémica como del individualismo asocial. Es aquí cuando el autor propone una tesis estimulante y novedosa: al entender a la política y a la teoría social como producciones culturales, las definiciones que cada una de ellas hacen sobre lo real tienen efectos mayúsculos sobre la sociedad. Sobre todo en la época actual, donde la demanda por nombrar e interpretar los cambios sociales en curso está fuertemente instalada (No en vano Nietzsche señaló que 'poderosos son aquellos que erigieron en ley los nombres de las cosas'). La propuesta de Lechner viene a ser entonces una reivindicación de la labor intelectual y de la reflexión política. Al tomarse en cuenta las nuevas formas de relacionarse e imaginarse que tienen las personas, se abre un espacio para la definición de un sentido en común. Visto así, la (re)construcción de un nosotros ciudadano depende en el día de hoy de las posturas que tanto la teoría social como la política adoptan frente a cuatro antinomias inherentes a la interpretación actual sobre el cambio social: 1) subjetividad social versus naturalización; 2) imaginario democrático versus fragmentación social; 3) espacio público versus retracción privatista; y por último, 4) horizontes de futuro versus presente permanente.

A modo de cierre, cabe señalar que este último libro de Norbert Lechner engarza con toda su trayectoria intelectual. La constante preocupación del autor sobre la particularidad de América Latina reaparece aquí ya en el título de la obra. Hacer referencia a 'las sombras del mañana' implica que para poder proyectar un futuro hay que hacerse cargo de la historia singular de nuestro continente. Y la labor tanto intelectual como política está llamada a cumplir esta tarea. Sólo cuando una sociedad es capaz de pensarse a si misma aumentan sus capacidades de autodetermina- 
ción. En este sentido, poner atención en la dimensión subjetiva de la política no es otra cosa que la fórmula a través de la cual se puede hacer para que la sociedad sea actora (sujeto) y no una mera espectadora (objeto) de las transformaciones en curso.

Cristóbal Rovira Kaltwasser 